J. Lake Sci. (湖泊科学), 2013, 25(5): 756-764

http: //www.jlakes.org. E-mail : jlakes@niglas. ac.cn

(c) 2013 by Journal of Lake Sciences

\title{
6200 年来六盘山天池磁学特征及环境重建
}

\author{
张欣佳 ${ }^{1}$, 孙惠玲 ${ }^{2}$, 吴 铎 $^{1}$, 张晓楠 ${ }^{1}$, 周爱锋 ${ }^{1 * *}$ \\ ( 1 : 兰州大学西部环境与气候变化研究院,兰州 730000) \\ ( 2 : 云南师范大学旅游与地理科学学院, 昆明 650500 )
}

\begin{abstract}
摘 要: 本文对六盘山天池长 $11 \mathrm{~m}$ 的 GSA 孔湖泊沉积岩芯样品进行了磁化率、非磁滞剩磁、等温剩磁测试. 结果表明 GSA 孔岩芯磁性矿物主要是亚铁磁性及反铁磁性矿物. 六盘山天池湖泊沉积物的磁性参数变化主要受控于两种模式: 整 体而言, 高 (低) 粉尘输人指示了夏季风弱 (强), 成壤作用强 (弱) 指示夏季风强(弱). 质量磁化率 $\chi$ 等参数清晰地记录了

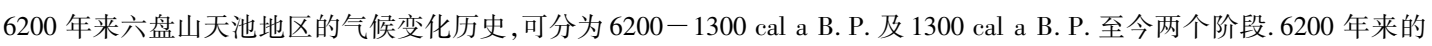
六盘山天池湖泊沉积物磁学数据在千年时间尺度上基本与东部季风区变化趋势相似. 但是在百年时间尺度上有着较大 的差异,这是由于六盘山天池地区的气候变化不仅仅受控于夏季风, 同时还受到人类活动导致的黄土高原植被覆盖变 化、冬季风变化等因素的影响.
\end{abstract}

关键词: 气候变化;六盘山天池; 磁学参数;夏季风; 黄土高原植被覆盖

\section{Magnetic characteristics and palaeoenvironment reconstructions over the past 6200 years of Lake Tianchi of Liupan Mountain}

\author{
ZHANG Xinjia ${ }^{1}$, SUN Huiling ${ }^{2}$, WU Duo ${ }^{1}$, ZHANG Xiaonan ${ }^{1}$ \& ZHOU Aifeng ${ }^{1}$ \\ (1: Research School of Arid Environment and Climate Change, Lanzhou University, Lanzhou 730000, P. R. China) \\ (2: College of Tourism and Geography, Yunnan Normal University, Yunnan 650500, P. R. China)
}

\begin{abstract}
In this paper we studied the core GSA $(11 \mathrm{~m})$ which was taken from Lake Tianchi of Liupan Mountain in the areas of magnetic susceptibility, anhysteretic remanent magnetisation, and isothermal remnant magnetization. The results show there are two kinds of magnetic minerals in the GSA: ferromagnetic and anti-ferromagnetism. The changes of sedimentary magnetic characteristics of Lake Tianchi are dominated by two patterns: high (low) dust input showing weak (strong) summer monsoon, and strong (weak) soil development showing strong (weak) summer monsoon. Magnetic susceptibility $\chi$, which has recorded the climate change history of study area, can be divided into two parts: from 6200 to $1300 \mathrm{cal}$ a B. P. , from $1300 \mathrm{cal}$ a B. P. to present. The climate changes in the past 6200 years in the study area were similar to that in the monsoon area in millennial time scales, but much different in century time scales. The reasons could be that the climate of study area was not only controlled by summer monsoon, but also by other factors, such as winter monsoon and human activities which lead to the changes in vegetation of the Loess Plateau.
\end{abstract}

Keywords: Climate change; Lake Tianchi of Liupan Mountain; magnetic parameter; summer monsoon; vegetation of Loess Plateau

中全新世以来,全球气候明显比早全新世温暖了许多,出现了全球性的高温期 ${ }^{[1]}$. 研究表明过去 6000 年里地球轨道参数 (insolation) 在千年尺度上的变化导致太阳能重新分配, 从而使得北半球夏季赤道辐合带 南移 ${ }^{[1]}$. 这一变化伴随着亚非地区季风系统的减弱, 进而导致这两个大洲气候干旱化与荒漠化 ${ }^{[1-3]}$. 而轨道 参数变化的同时还导致了太平洋地区的 ENSO 及大西洋地区 NAO 的变化一-ENSO 活动增强, NAO 指数变 为负值 ${ }^{[1,4-7]}$. 整体而言,中全新世以来全球气候不存在如冰期一间冰期一般的气候旋回 ${ }^{[1]}$,但是在全球范围

* 国家重点基础研究发展计划 “973” 项目 (2010CB950202, 2012CB956102) 和国家自然科学基金重点项目 $(41130102,41271221,41201203)$ 联合资助. 2012-10-22 收稿;2013-02-25 收修改稿. 张欣佳,女,1988 年生, 硕 士研究生;E-mail: saintfans@ 163.com.

** 通信作者;E-mail : zhouaf@ lzu. edu.cn. 
内依然存在 $4800-4600 、 2800-2600 、 1650-1450$ 和 $650-450 \mathrm{cal}$ a B. P. 四次显著冷事件 ${ }^{[8]}$. 由于我国地域 辽阔,在过去 6000 年里其气候与环境不仅随着时间而变化, 同时还伴随着明显的空间差异 ${ }^{[9-11]}$. 如夏季风主 要影响着我国东南季风区的气候,而西北干旱区气候则受到西风的显著影响 ${ }^{[12]}$. 六盘山位于黄土高原中部 地区,属于我国东南季风区与西北干旱区之间的过渡区. 研究表明该地区整体气候受夏季风影响,其气候记 录大体趋势与季风区石笋记录一致; 同时受到多方因素的影响,气候变化相对东部季风区更为复杂 ${ }^{[13-14]}$. 六 盘山与黄土高原地区自古以来就有人类活动存在, 人类活动无疑会对研究区环境变化起重要作用. 1980 s 初, Oldfield 和 Thompson 等完成了新学科 “环境磁学” 的系列开创性研究工作 ${ }^{[15-19]}$. 由于磁学参数测量的无 破坏性、快捷性和灵活性,环境磁学技术广泛地应用到各种古环境问题的研究中,如深海沉积、湖泊沉积、黄 土沉积等 ${ }^{[19-20]}$. 根据湖泊类型、沉积物来源以及沉积后的后期改造作用和生物自生作用的不同, 磁学参数所 指示的意义也不同 ${ }^{[21-23]}$. 如山西宁武公海沉积物主要来源于湖盆周围, 沉积物沉积到湖泊后受到的后期改 造、生物自生作用影响较弱,因此其质量磁化率高值指示强夏季风 ${ }^{[24]}$. 六盘山天池地处季风边缘区, 磁性矿 物来源复杂, 沉积物磁学参数所指示的气候意义不能一概而论. 本文将详细分析六盘山天池湖泊沉积样品 的磁学参数, 以研究过去 6200 年里夏季风强度变化及研究区内气候环境变化, 并深人讨论人类活动对研究 区气候环境的影响.

\section{1 研究区概况}

六盘山天池 $\left(35^{\circ} 15^{\prime} \mathrm{N}, 106^{\circ} 18^{\prime} \mathrm{E}\right.$; 海拔 $\left.2430 \mathrm{~m}\right)$ 又称关山天池, 位于甘肃省庄浪县境内, 为一小型间歇性 排水堰塞淡水湖 (图 1a,d). 湖泊面积 $2 \times 10^{4} \mathrm{~m}^{2}$, 流域面积 $20 \times 10^{4} \mathrm{~m}^{2}$, 最大水深 $8.2 \mathrm{~m}$. 主要补给方式为降 水补给. 六盘山天池流域年均降水量 $615 \mathrm{~mm}$, 年均温度 $3.4^{\circ} \mathrm{C}$. 植被以灌丛和草甸为主 ${ }^{[13]}$.
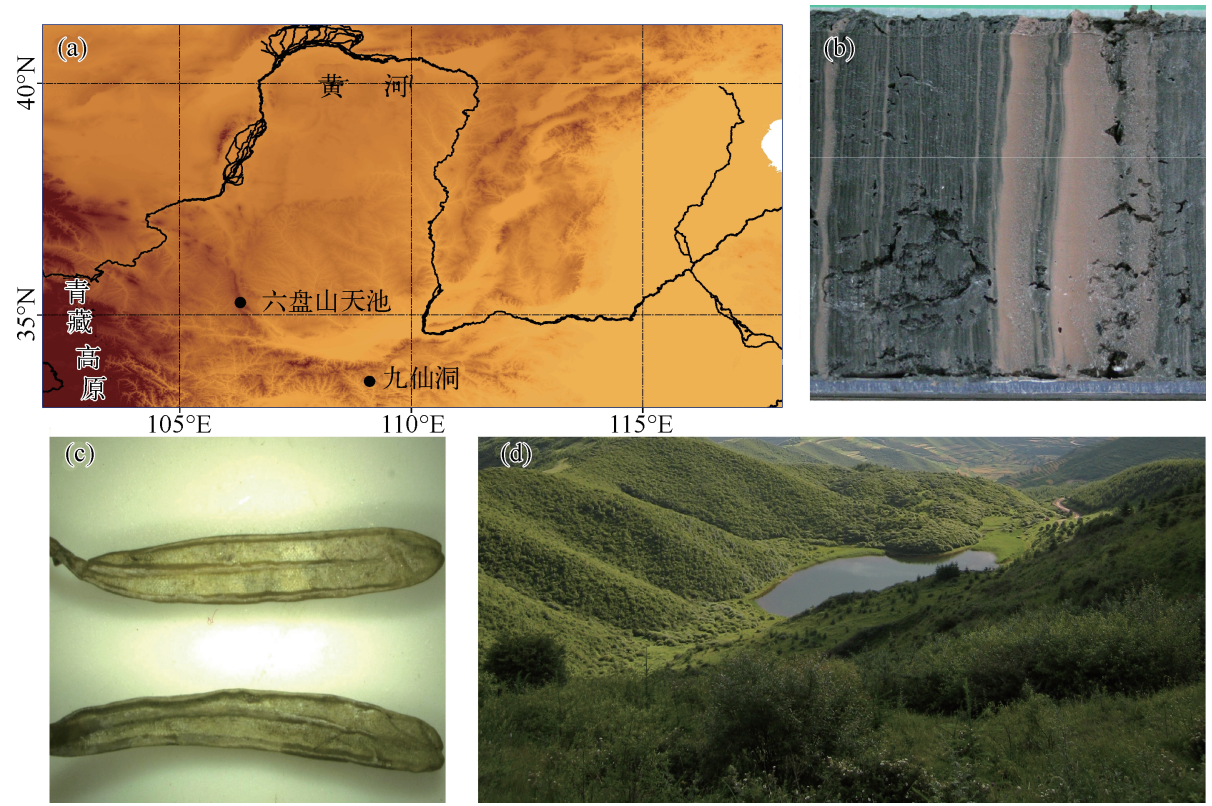

图 1 六盘山天池地理位置 $(a) 、$ 部分岩芯纹层结构 $(b)$ 、冷杉植物残体 $(\mathrm{c})$ 和流域概况 $(\mathrm{d})$

Fig. 1 Location of Lake Tianchi of Liupan Mountain(a), photo of sediment core (b), photo of remain fir needles (c), photo of Lake Tianchi catchment(d)

\section{2 材料与方法}

2007 年 11 月, 在湖心处使用奥地利 UWITEC 平台钻进行岩芯钻探, 获得两根长约 $11 \mathrm{~m}$ 的平行钻孔, 从 顶部至底部出现数段连续清晰的湖相纹层状沉积 (图 1b). 纹层中深色部分以有机质为主, 浅色部分主要是 
碎屑物质. 同时在岩芯中发现了大量且连续的陆生高等植物残体 (从 $162 \mathrm{~cm}$ 处至底部均有发现), 如完好的 冷杉叶片 (图 1c), 为高分辨率的测年提供了极佳的陆源植物 ${ }^{14} \mathrm{C}$ 测年材料.

本文主要进行了环境磁学指标的测量. 样品按 $1 \mathrm{~cm}$ 间隔进行分样, 利用冷冻干燥仪器干燥后将样品装 人 $2 \mathrm{~cm} \times 2 \mathrm{~cm} \times 2 \mathrm{~cm}$ 无磁塑料盒中称重, 测量. 前 $100 \mathrm{~cm}$ 样品全部测量, 之后的样品间隔进行测量. 磁性参 数按照 Dearing 描述的方法来测量, 并计算相关参数 ${ }^{[25]}$. 使用 Bartington MS2 磁化率仪测量低频磁化率 $\left(\chi_{\mathrm{LF}}\right)$ 和高频磁化率 $\left(\chi_{\mathrm{HF}}\right)$, Molspin 旋转磁力仪及脉冲磁场发生器测量非磁滞剩磁 ( ARM, 交变磁场峰值 $100 \mathrm{mT}$, 直流磁场 $0.05 \mathrm{mT}$ )、 $1 \mathrm{~T}$ 磁场的饱和等温剩磁 (SIRM) 以及 $-300 \mathrm{mT}$ 磁场下的等温剩磁 ( IRM). 计算质量磁 化率 $(\chi) 、$ 、非磁滞磁化率 $\left(\chi_{\mathrm{ARM}}\right) 、 \mathrm{~S}$ 比值 $\left(\mathrm{S}_{-300}\right)$ 、频率磁化率 $\left(\chi_{\mathrm{FD}}\right)$ 以及比值参数 $\chi_{\mathrm{ARM}} / \chi$ 、SIRM $/ \chi 、 \chi_{\mathrm{ARM}} / \mathrm{SIRM}$ 等. 以上参数的测定均在兰州大学西部环境教育部重点实验室完成.

\section{3 实验结果}

\section{1 年代结果}

${ }^{14} \mathrm{C}$ 测年材料全部选用 GSA 孔岩芯中保存完好的冷杉叶片 (图 1c), 在兰州大学西部环境教育部重点实 验室年代学实验室中合成石墨, 然后送至北京大学 AMS 实验室进行测量. ${ }^{14} \mathrm{C}$ 结果用 OXCAL 4. 1 程序 ${ }^{[26]}$, 采用 Intcal 04 校正数据 ${ }^{[27]}$ 进行日历年龄校正, 建立六盘山天池 GSA 孔可靠的 ${ }^{14} \mathrm{C}$ 年代框架, 跨度为 $6200 \mathrm{cal}$ a B. P. , 年代一深度模型见文献[14].

\section{2 环境磁学参数结果}

除频率磁化率 $\chi_{\mathrm{FD}}$ (图 2g) 外所有磁学数据趋势一致, 随着深度的变化可以划分为 3 个阶段. (1) 1093 $532 \mathrm{~cm}$ : 各组数据变化幅度不明显, 质量磁化率 $\chi$ (图 2a)、非磁滞剩磁磁化率 $\chi_{\mathrm{ARM}}$ (图 $2 \mathrm{~b}$ )、饱和等温剩磁 $\operatorname{SIRM}\left(\right.$ 图 2c )、 $\chi_{\mathrm{ARM}} / \chi$ (图 2f)、 $\chi_{\mathrm{ARM}} / \operatorname{SIRM}$ (图 2e) 的变化范围分别为 $6.8 \times 10^{-8} \sim 28.3 \times 10^{-8} \mathrm{~m}^{3} / \mathrm{kg} 、 9.0 \times$ $10^{-8} \sim 111.9 \times 10^{-8} \mathrm{~m}^{3} / \mathrm{kg} 、 180.5 \times 10^{-5} \sim 946.8 \times 10^{-5} \mathrm{Am}^{2} / \mathrm{kg} 、 0.19 \sim 7.50 、 0.01 \times 10^{-3} \sim 0.37 \times 10^{-3} \mathrm{~m} / \mathrm{A}$; 平 均值分别为 $15.6 \times 10^{-8} \mathrm{~m}^{3} / \mathrm{kg} 、 35.9 \times 10^{-8} \mathrm{~m}^{3} / \mathrm{kg} 、 354.6 \times 10^{-5} \mathrm{Am}^{2} / \mathrm{kg} 、 2.2$ 和 $0.1 \times 10^{-3} \mathrm{~m} / \mathrm{A}$, 该阶段数值 为整个岩芯最低值; (2) $531 \sim 304 \mathrm{~cm}$ : 各组数据缓慢上升, 升幅不明显, 变化范围分别为 $8.3 \times 10^{-8} \sim 24.4 \times$ $10^{-8} \mathrm{~m}^{3} / \mathrm{kg} 、 21.5 \times 10^{-8} \sim 208.5 \times 10^{-8} \mathrm{~m}^{3} / \mathrm{kg} 、 201.5 \times 10^{-5} \sim 728.2 \times 10^{-5} \mathrm{Am}^{2} / \mathrm{kg} 、 0.8 \sim 10.2$ 和 $0.04 \times$ $10^{-3} \sim 0.50 \times 10^{-3} \mathrm{~m} / \mathrm{A}$; 平均值分别为 $18.1 \times 10^{-8} \mathrm{~m}^{3} / \mathrm{kg} 、 94 \times 10^{-8} \mathrm{~m}^{3} / \mathrm{kg} 、 407.3 \times 10^{-5} \mathrm{Am}^{2} / \mathrm{kg}$ 、 4.8 和 $0.21 \times 10^{-3} \mathrm{~m} / \mathrm{A}$, 整体数值依然偏低; (3) $303 \sim 0 \mathrm{~cm}$ : 各组数据显著上升, 升幅明显, 变化范围分别为 $13.6 \times$ $10^{-8} \sim 50.5 \times 10^{-8} \mathrm{~m}^{3} / \mathrm{kg} 、 18.1 \times 10^{-8} \sim 1456.9 \times 10^{-8} \mathrm{~m}^{3} / \mathrm{kg} 、 246.6 \times 10^{-5} \sim 1338.7 \times 10^{-5} \mathrm{Am}^{2} / \mathrm{kg} 、 1.2 \sim$ 28.8 和 $0.06 \times 10^{-3} \sim 1.09 \times 10^{-3} \mathrm{~m} / \mathrm{A}$; 平均值分别为 $29.8 \times 10^{-8} \mathrm{~m}^{3} / \mathrm{kg} 、 552.4 \times 10^{-8} \mathrm{~m}^{3} / \mathrm{kg}$ 、745.3 $\times$ $10^{-5} \mathrm{Am}^{2} / \mathrm{kg} 、 16.3$ 和 $0.64 \times 10^{-3} \mathrm{~m} / \mathrm{A} . \chi 、 \chi_{\mathrm{ARM}}$ 在 $13 \mathrm{~cm}$ 处, SIRM 在 $20 \mathrm{~cm}$ 处, $\chi_{\mathrm{ARM}} / \chi 、 \chi_{\mathrm{ARM}} / \mathrm{SIRM}$ 在 $23 \mathrm{~cm}$ 处达到最高值, 随后下降至较低值.

环境磁学指标 $\mathrm{S}_{-300}$ (图 2d) 可以用来衡量低矫顽力铁磁性矿物与高矫顽力反铁磁性矿物的相对比 例 ${ }^{[29-30]}$, 其中高值表明亚铁磁性矿物相对含量较高 ${ }^{[31]}$. GSA 孔样品的 $\mathrm{S}_{-300}$ 比值变化范围较大, 在 $10 \% \sim$ 90\% 范围内频繁波动, 表明亚铁磁性矿物和反铁磁性矿物均为载磁矿物. 变化趋势与 $\chi$ 和 SIRM 完全一致, 表明六盘山天池 GSA 孔沉积物中的亚铁磁性矿物比例逐渐升高. 且 SIRM 与 $\chi$ 相关性很好 $\left(R^{2}=0.89\right)$, 表 明所有样品的磁性颗粒主要为亚铁磁性矿物 ${ }^{[19,32]}$.

$87 \%$ 样品的频率磁化率 $\chi_{\mathrm{FD}}$ (图 2 $\mathrm{g}$ ) 小于 5\%, 整体平均值为 $3.07 \%$, 表明样品的磁性颗粒组合中超顺磁 $(\mathrm{SP})$ 颗粒没有或很少 ${ }^{[18]}$. SIRM、 $\chi 、 S_{-300}$ 趋势一致, 表明 SP 颗粒对样品的磁性强弱贡献不大 ${ }^{[19]}$, 且 Dearing 图 (图 3) 显示落在 $\mathrm{SSD} / \mathrm{SP}$ 过渡范围内的样品数量为零. 结合 $\chi_{\mathrm{FD}}$ 数据可以认为 $\mathrm{GSA}$ 孔样品中不含 $\mathrm{SP}$ 颗粒. 在此前提下, $\chi_{\mathrm{ARM}} / \chi$ 与 $\chi_{\mathrm{ARM}} / \mathrm{SIRM}$ 可以指示细颗粒亚铁磁性矿物, 磁性矿物颗粒越小, 两项比值参数越

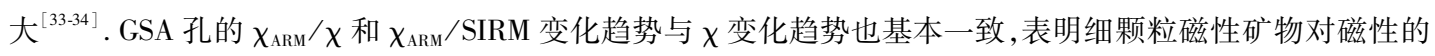
增强起着重要的作用.

考虑到沉积物粒度特征对湖泊沉积物磁化率的影响, GSA 孔样品的粒度数据 (中值粒径) 除了在个别深 度出现明显峰值外, 整体呈水平状, 从底部到顶部无变化趋势, 因此认为磁学参数与粒度并无相关性 (粒度 数据另文发表, 本文不再详细论述 ${ }^{[35]}$ ). 


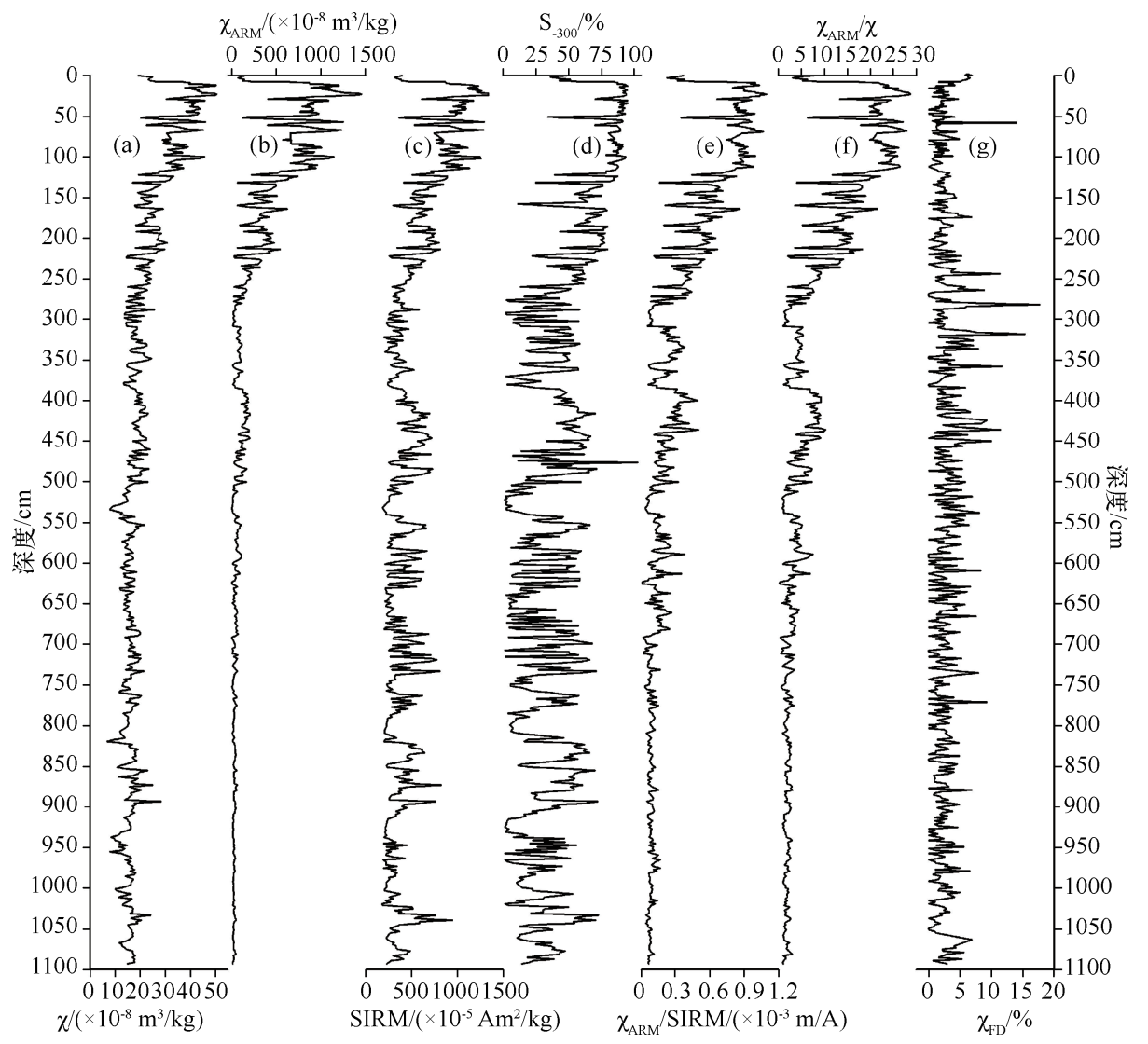

图 $2 \mathrm{GSA}$ 孔 $\chi(\mathrm{a}) 、 \chi_{\mathrm{ARM}}(\mathrm{b}) 、 \operatorname{SIRM}(\mathrm{c}) 、 \mathrm{~S}_{-300}(\mathrm{~d}) 、 \chi_{\mathrm{ARM}} / \operatorname{SIRM}(\mathrm{e}) 、 \chi_{\mathrm{ARM}} / \chi(\mathrm{f}) 、 \chi_{\mathrm{FD}}(\mathrm{g})$ 垂向变化

Fig. 2 Vertical changes of $\chi(a), \chi_{\text {ARM }}(b), \operatorname{SIRM}(c), S_{-300}(d), \chi_{\text {ARM }} / \operatorname{SIRM}(e), \chi_{\text {ARM }} / \chi(f)$, $\chi_{\mathrm{FD}}(\mathrm{g})$ of GSA core samples

依据 Dearing 图 (图 3) 能够有效区分不同磁畴的沉积物磁性颗粒的大小 ${ }^{[36]}$. GSA 孔岩芯样品有近 $60 \%$

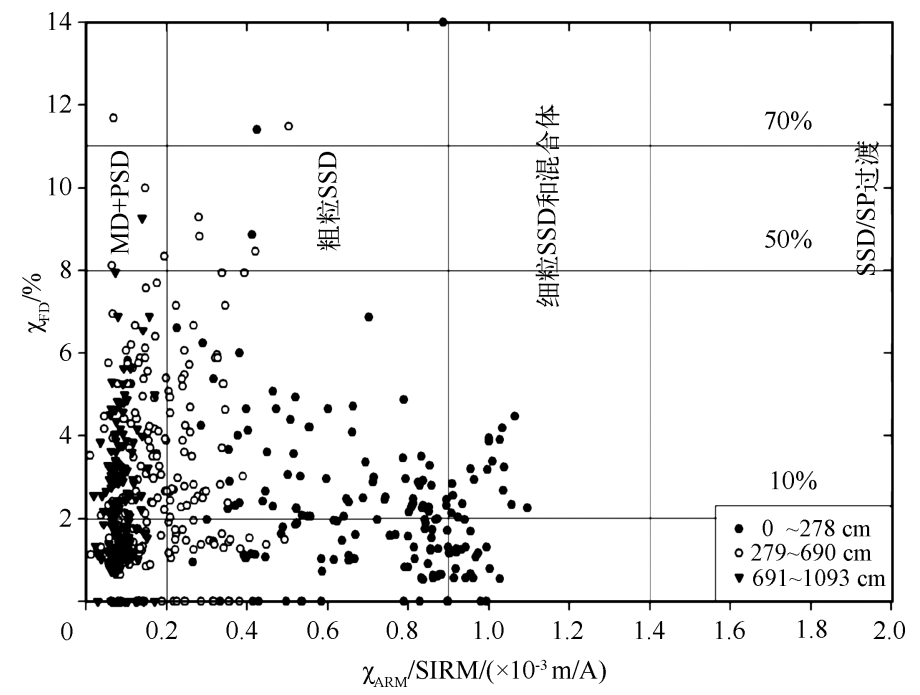

图 3 GSA 孔样品的 Dearing 图

Fig. 3 Dearing plot of GSA core samples 
落在 Dearing 图的 MD + PSD 范围, 这些样品由全部 $691 \sim 1093 \mathrm{~cm}$ 段样品及部分 $279 \sim 690 \mathrm{~cm}$ 段样品组成. 另有超过 $30 \%$ 的样品落在了粗粒 SSD 范畴, 由剩余的 $279 \sim 690 \mathrm{~cm}$ 段样品及大部分 $0 \sim 278 \mathrm{~cm}$ 段样品组成. 剩下少量样品位于细粒 SSD 范围内, 均为顶部 $0 \sim 278 \mathrm{~cm}$ 段样品. 结果表明 GSA 孔岩芯样品磁性颗粒粒度 从底部到顶部逐渐变细, 与 $\chi_{\mathrm{ARM}} / \chi$ 和 $\chi_{\mathrm{ARM}} / \mathrm{SIRM}$ 两项比值参数指示的结果基本一致.

综上所述, 可得出结论: GSA 孔样品磁性颗粒以亚铁磁性和反铁磁性矿物为主. 底部主要是反铁磁性矿 物, 从底部至顶部亚铁磁性矿物比例逐渐升高, 同时细颗粒磁性矿物也逐渐增多.

\section{4 讨论}

湖泊中的磁性矿物一般来源于外源粉尘输人、湖盆集水区径流输人及湖泊自生作用, 此外后期氧化还 原作用 (早期成岩作用) 同样能导致磁性矿物发生变化 ${ }^{[19]}$. 早期成岩作用主要表现为有机质的分解、元素的 还原以及自生矿物的生成等. 在湖泊中, 有机质的氧化分解消耗大量的氧从而形成还原环境. 当沉积物中有 机质含量较高时, 原始沉积的磁性矿物中的铁的氧化物被还原分解, 形成二价铁离子, 而后硫酸盐中的硫元 素被还原 $\left(\mathrm{SO}_{4}^{2-} \rightarrow \mathrm{S}^{2-}\right)$; 二价铁离子 $\left(\mathrm{Fe}^{2+}\right)$ 与硫化氢 $\left(\mathrm{H}_{2} \mathrm{~S}\right)$ 反应生成铁的硫化物系列: 磁黄铁矿 $\rightarrow$ 胶黄铁矿 $\rightarrow$ 黄铁矿, 一般认为铁的硫化物是这一时期的代表性矿物 ${ }^{[1,3740]}$. 磁黄铁矿和黄铁矿的 SIRM/ $\chi$ 值 一般在 $100 \mathrm{kA} / \mathrm{m}$ 左右, 胶黄铁矿的 $\mathrm{SIRM} / \chi$ 值为 $40 \mathrm{kA} / \mathrm{m}^{[32,4142]}$, GSA 孔样品的 $\mathrm{SIRM} / \chi$ 平均值为 $22 \mathrm{kA} / \mathrm{m}$, 表明样品中不含或含微量的铁硫化物. 同时成岩作用期间沉积环境处于富含细菌的还原条件下, 许多较大 的有机分子和无机分子都会被破坏, 只保存最稳定的部分 (如木质部分), 而在 GSA 孔岩芯中从底部到顶部 均发现了大量的完整冷杉叶片 ${ }^{[37]}$. 且早期成岩作用所生成的自生磁性矿物多为细粒 SSD 颗粒 ${ }^{[19]}$, GSA 孔样 品中细粒 SSD 范畴内的磁性矿物很少, 且集中在顶部, 更可能是来源于黄土高原地区. 因此可以认为 GSA 孔 岩芯沉积物中的磁性矿物并未受到早期成岩作用改造, 湖泊沉积物真实记录了研究区内过去 6200 年的磁 学特征.

GSA 孔岩芯沉积物中的磁性矿物主要来源为外源粉尘输人和湖盆集水区径流输人. GSA 孔磁学数据显 示 $\chi 、 \chi_{\text {ARM }}$ SIRM 与 $\mathrm{S}_{-300}$ 在 6200-1300 cal a B. P. 相对较低, Dearing 图也显示该段样品中磁性颗粒以相对较 粗的 SSD、MD + PSD 为主. 同时 $\chi 、 S_{-300}$ 与 $\chi_{\mathrm{ARM}} / \chi$ 的变化趋势一致 (图 3), 这表明磁化率值高的磁性颗粒较 细, 这种情况通常与土壤发育有关 ${ }^{[24]}$. 关于山西宁武公海的研究表明 ${ }^{[24]}$ 夏季风越强, 土壤发育程度越高, 进 人湖泊的磁性矿物越多, 样品的 $\chi$ 值就越高. 因此可以认为 6200-1300 cal a B. P., GSA 孔岩芯的磁学数据 反映湖泊集水区土壤发育的强弱, 间接指示夏季风强度变化. $1300 \mathrm{cal}$ a B. P. 后, $\chi 、 \chi_{\mathrm{ARM}} 、 S I R M$ 与 $\mathrm{S}_{-300}$ 大幅 度升高, Dearing 图显示该阶段沉积物中的磁性颗粒以细粒 SSD 为主. 前后两阶段磁学数据出现明显差异, 可 能是磁性矿物来源方式改变导致的. 黄土高原地区在成壤过程中形成了大量细粒磁性矿物, 且黄土样品的 $\chi_{\mathrm{FD}}$ 一般在 $0 \sim 4 \%$ 之间 ${ }^{[4243]}$. 推测对质量磁化率起到了重要作用的细颗粒亚铁磁性矿物主要来源于黄土高原地区

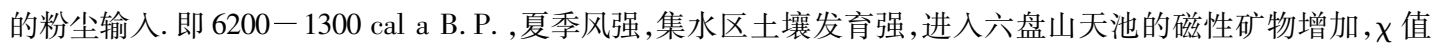
升高, 磁化率反映的是夏季风的强弱, $\chi$ 高 (低) 值指示气候湿润 (干旱), 夏季风强(弱). $1300 \mathrm{cal}$ a B. P. 至 今, 夏季风弱, 但磁化率却不同于上述变化模式, 明显升高. 来源于黄土高原的黄土一古土壤具有相对很高的 磁化率值 ${ }^{[4344]}, \chi$ 高达 $500 \times 10^{-8} \mathrm{~m}^{3} / \mathrm{kg}$, 这种流域外的磁性矿物输人可导致湖泊沉积物 $\chi$ 值显著升高. 六盘 山天池现代流域表土磁化率在 $14 \times 10^{-8} \sim 30 \times 10^{-8} \mathrm{~m}^{3} / \mathrm{kg}$ 之间 ${ }^{[13]}$, 介于成壤作用和粉尘输人, 表明两种输 人方式是共同作用的.

将 $\chi$ 与同一岩芯得出的落叶树孢粉数据及甘肃省历史时期人口数量 (图 4) 进行对比 ${ }^{[28]}$, 落叶树孢粉曲 线 (图 4b) 在 6200-1300 cal a B. P. 期间呈下降趋势, 指示夏季风减弱, 研究区气候趋于干旱; $\chi$ (图 4a) 在同 一时期内变化趋势不明显, 但是大部分时期与落叶树狍粉数据具有相同的趋势, 支持 $\chi$ 高 (低) 值指示气候 湿润 (干旱), 夏季风强(弱). $1300 \mathrm{cal}$ a B. P. 后, 落叶树狍粉曲线整体呈下降趋势, 该时期季风持续减弱, $\chi$ 却异常升高, 依据前面的分析, 该时期主要植被类型已经退化, 研究区气候更加干旱, 夏季风持续减弱, 与 $\chi$

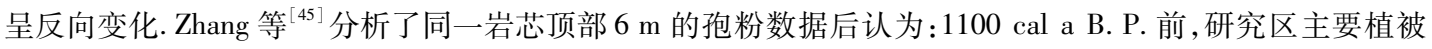

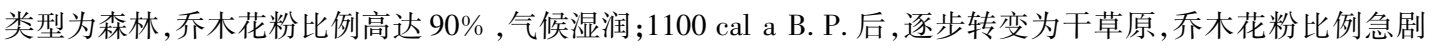
下降, 草本和灌木植物花粉比例增加, 气候干旱, 且出现了大量谷物花粉和炭屑, 表明人类活动强烈干扰了 
研究区内植被和景观, 甘肃省历史时期人口数据 (图 4c) 也显示该时期人口数量呈明显增长态势 ${ }^{[46]}$. 落叶树 孢粉曲线在 800-450 cal a B. P. 期间呈反向增长, Zhang 等 ${ }^{[45]}$ 称之为森林再生期,认为南宋一元一明初的长期 战乱导致农田荒废且人口锐减, 为森林的恢复提供了条件, 图 4c 显示同时期人口数量的确在减少. 该时期 磁性矿物来源由于气候持续干旱及黄土高原地区植被破坏转变为外源粉尘输人, 同时 $\chi$ 还受到人类活动的 强烈干扰, 能够指示人类活动的强弱.

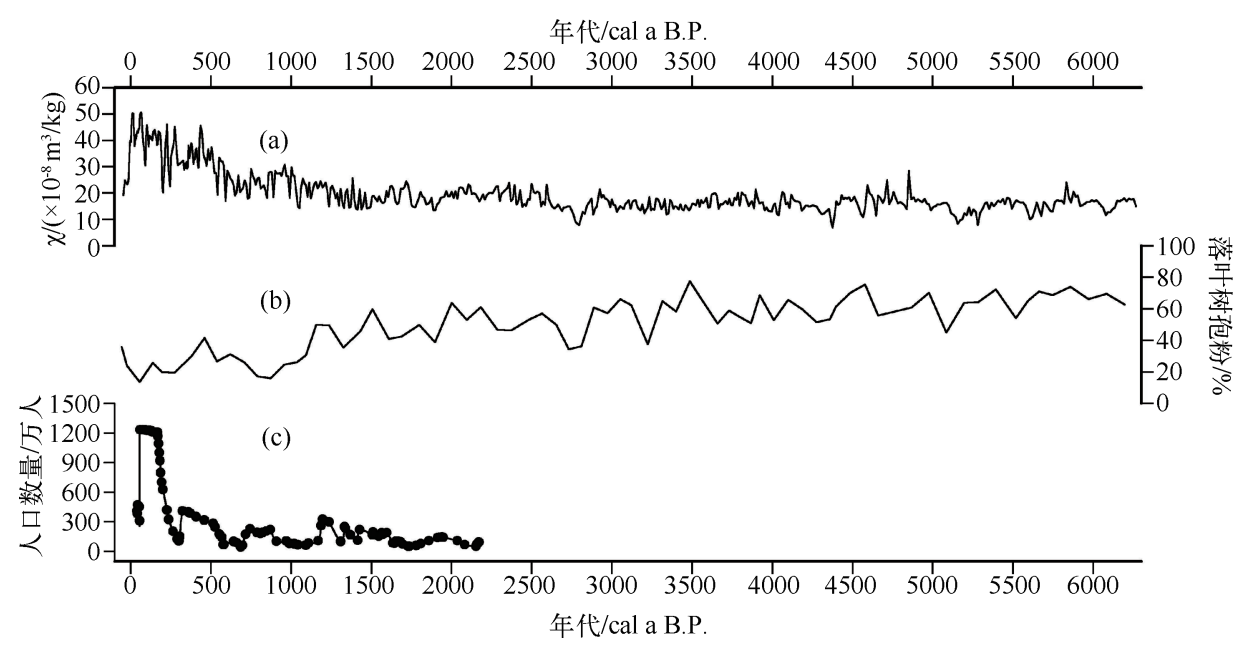

图 4 GSA 孔 $\chi(a)$ 、落叶树狍粉百分比 ${ }^{[28]}(\mathrm{b})$ 与甘肃省历史时期人口数量 ${ }^{[46]}(\mathrm{c})$ 对比

Fig. 4 Comparison of GSA core $\chi(a)$, deciduous trees pollen record ${ }^{[28]}(\mathrm{b})$ and population of Gansu Province during historical periods ${ }^{[46]}$ (c)

将九仙洞 ${ }^{[11]}$ (图 5b) 与董哥洞 ${ }^{[47]}$ (图 5c) 的石笋 $\delta^{18} O$ 记录、 $\Delta \mathrm{TSI}^{[48]}$ (图 5d) 及 $\mathrm{GSA} 孔 \chi($ 图 5a) 进行对

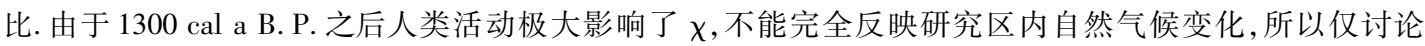
6200-1300 cal a B. P. 时期. 两个石笋 $\delta^{18} \mathrm{O}$ 记录的基本变化趋势一致,显示亚洲夏季风逐渐减弱. 董哥洞位 于我国南部, $\delta^{18} \mathrm{O}$ 记录直接指示区域内夏季降水量, 间接指示亚洲夏季风强度 ${ }^{[47]}$. Wang 等 ${ }^{[47]}$ 认为 $6200-$

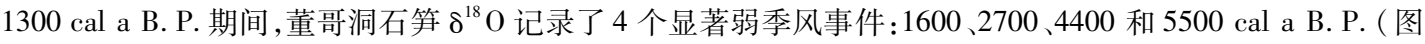

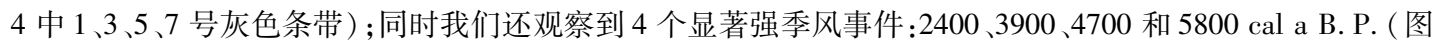
4 中 $2 、 4 、 6 、 8$ 号灰色条带), 这 8 次显著季风事件在 $\chi$ 中均有响应. 九仙洞位于我国中部, 距离六盘山天池 $317 \mathrm{~km}$, 其石笋 $\delta^{18} \mathrm{O}$ 记录同样受到亚洲季风强烈影响,直接反映区域内夏季降水,间接指示亚洲夏季风强 度 ${ }^{[11]}$. 但是由于区域自然气候和地理位置等因素影响, 整体变化趋势与董哥洞石笋数据一致,短时间尺度上

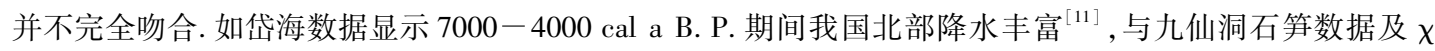
一致, 而董哥洞石笋数据呈明显减弱趋势, 表明即使是在长时间尺度上, 我国南北气候还是存在差异的. 九

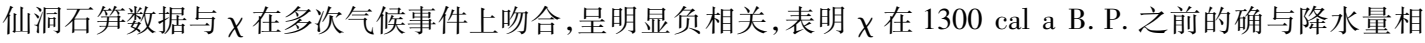
关:气候湿润 (干旱), 降水量高 (低), $\chi$ 值高 (低). 图 5 还显示 8 次强/弱季风事件分别对应着 $\Delta \mathrm{TSI}^{[48]}$ 的高/ 低值, Wang 等 ${ }^{[47]}$ 也认为亚洲季风变化与太阳能量输出有一定的相关性: 百年或数百年尺度上石笋 $\delta^{18} \mathrm{O}$ 记 录变化极大的时期与 $\Delta$ TSI 是吻合的. 这是由于 $\Delta$ TSI 在一定程度上影响了热带辐合带 ( ITCZ) 的运动, 进而 驱动亚洲季风发生变化, 直观表现为降水量的改变, 从而间接影响了研究区气候和湖泊沉积状况. 由于研究 区位于内陆季风边缘区,其气候在 6200 年间与董哥洞石笋指示的夏季风变化趋势一致; 在 $\Delta$ TSI 驱动亚洲季 风发生显著变化的时期,研究区湖泊沉积物出现响应; 但在百年尺度上明显受区域性气候影响, 如黄土高原 地区; 最近 1300 年更是受到了人类活动的强烈影响.

综上所述, 可以将过去 6200 年划分为两个阶段:

第一阶段, 6200-1300 cal a B. P. . 六盘山天池磁性矿物来源以成壤作用为主. 此时季风区的九仙洞、董哥 洞石笋氧同位素记录偏轻,指示夏季风较强. 且该时期出现了全球性高温期,我国西部冰川冻土大量融化,研 


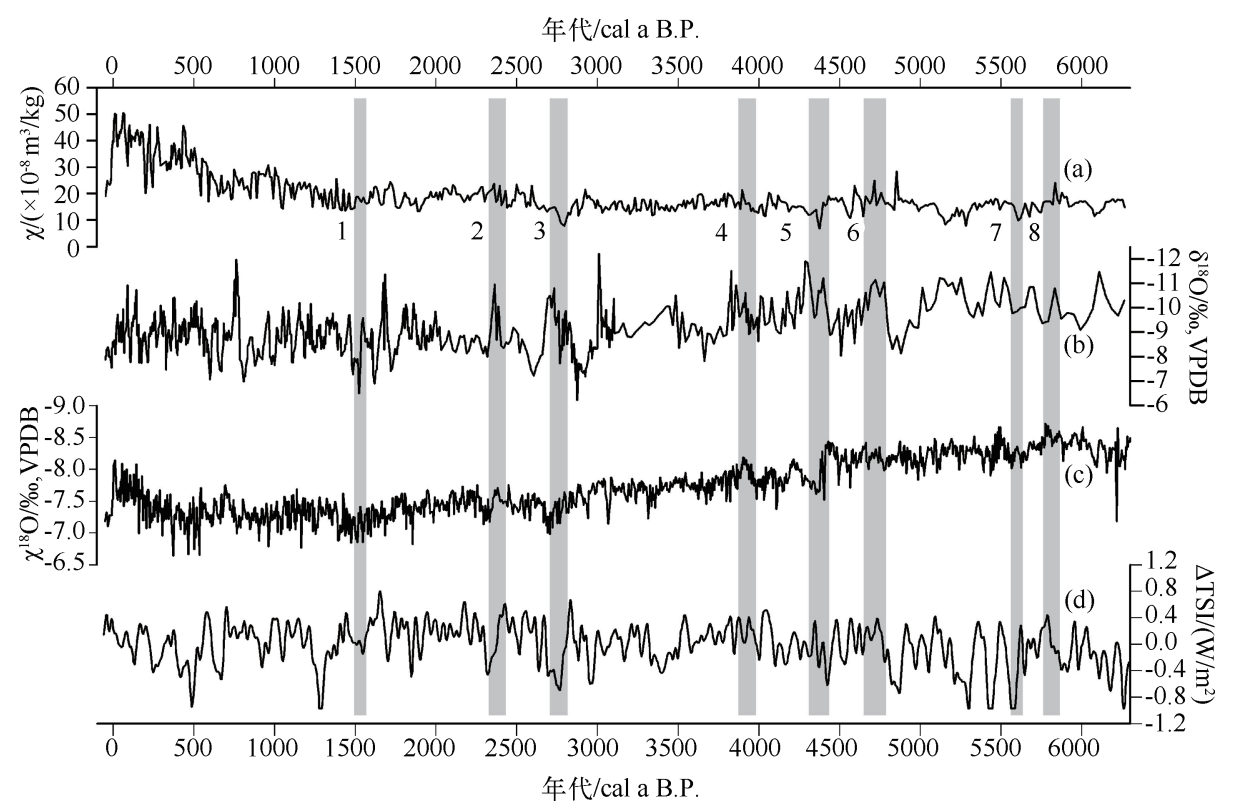

图 $5 \mathrm{GSA}$ 孔 $\chi(\mathrm{a})$ 与九仙洞 ${ }^{[11]}(\mathrm{b})$ 、董哥洞 ${ }^{[47]}(\mathrm{c}) \delta^{18} \mathrm{O}$ 数据及 $\Delta \mathrm{TSI}^{[48]}(\mathrm{d})$ 对比

Fig. 5 Comparison of GSA core $\chi(a), \delta^{18} \mathrm{O}$ record of Jiuxian cave ${ }^{[11]}(\mathrm{b})$, Dongge cave ${ }^{[47]}(\mathrm{c})$ and $\Delta \operatorname{TSI}^{[48]}(\mathrm{d})$

究区气候湿润 ${ }^{[49]}$, 夏季降水量高. $\chi$ 值反映了 4 个显著弱季风事件:1600、2700、4400 和 5500 cal a B. P.;4 个

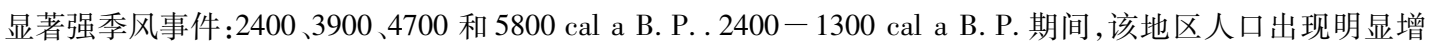
长 $^{[14,46]}$, 农耕文明进一步发展, 黄河中游森林覆盖率从 $53 \%$ 下降至 $42 \%{ }^{[50]}$, 人类活动对区域气候的影响开 始逐渐增强,但并不显著.

第二阶段, $1300 \mathrm{cal}$ a B. P. 至今. $\chi$ 值急剧升高, 六盘山天池中的磁性矿物来源于黄土高原粉尘输人. 高 $\chi$ 值指示夏季风减弱, 与九仙洞和董哥洞石笋数据变化一致, 孢粉数据 ${ }^{[45]}$ 也显示该时期研究区气候更加干旱, 植被类型退化为干草原. 由于在该时期发现了大量的谷物花粉和炭屑 ${ }^{[45]}$, 且人口数量急剧锬升 ${ }^{[46]}$, 认为 $x$ 受到了人类活动的强烈影响, 不能完全反映研究区内的自然气候变化. 同时有研究证实 ${ }^{[50]}$ 唐宋时期 (1300-677 cal a B. P. ) 黄土高原地区的天然植被开始大量消失, 沙漠向南扩张, 土地荒漠化加剧; 随后在 明清时期 (588-45 cal a B. P. ) 由于人类农耕活动而被破坏殆尽. 黄河中游森林覆盖率在唐宋时期下降至 $32 \%$, 明清时期下降至 4\% , 同时加之明中期 LIA 的作用, 黄土高原地区自然环境进一步恶化. 该时期 $\chi_{\text {ARM }} \times$ 和 $\chi_{\mathrm{ARM}} / \mathrm{SIRM}$ 大幅度上升, 表明湖泊沉积物中出现了大量细颗粒磁性矿物, 与黄土高原地区土壤组成成分 一致. 因此 $\chi$ 的急剧升高除了受到夏季风减弱影响之外,还与人类活动及黄土高原地区植被破坏紧密相关. $\chi$ 在 $13 \mathrm{~cm}$ 深度处迅速下降, $\chi_{\mathrm{ARM}} / \chi$ 和 $\chi_{\mathrm{ARM}} / \mathrm{SIRM}$ 也随之变化, 对应历史时期为 $1940 \mathrm{~s}$ 前后, 表明这一时期 沉积物中出现了大量粗颗粒磁性矿物. 由于大气粉尘中的磁性矿物以粗颗粒磁性矿物为主 ${ }^{[51]}$, 所以推测为 大气粉尘颗粒, 可能与近代以来的工业化发展有关.

\section{5 结论}

对六盘山天池 GSA 孔湖泊沉积物的环境磁学研究表明, 沉积物样品磁性颗粒的主要组成部分是亚铁磁 性及反铁磁性矿物, 磁性颗粒大小主要属于 MD + PSD 以及粗粒 SSD 范畴, 含有少量细粒 SSD 颗粒. 反铁磁 性矿物主要集中在岩芯中下部, 即 6200-1300 cal a B. P. 之前. 从底部至顶部亚铁磁性矿物比例逐渐升高, 同 时细颗粒磁性矿物也逐渐增多, 表明来源于黄土高原的细颗粒亚铁磁性矿物逐渐增多. 因此 $x$ 反映夏季风强 度对黄土高原地区气候的影响, 进而能够指示夏季风强弱变化: 6200-1300 cal a B. P., X 越高, 指示夏季风越

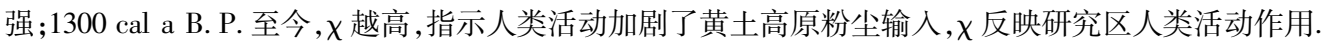


6200 年来六盘山天池湖泊沉积物的磁学数据的整体变化趋势基本与东部季风区相似. 在 $\Delta$ TSI 驱动亚 洲季风发生显著变化的时期,盘山天池湖泊沉积物出现响应; 但是在百年尺度上明显受区域性气候影响,如 黄土高原地区, 同时还受其他因素影响. 最近 1300 年来人类活动, 尤其是农耕活动, 强烈地影响了黄土高原 天然植被覆盖变化,进而影响区域内气候变化. 此外冬季风、西风等因素也起着一定的作用. 因此,要明确了 解内陆季风边缘区气候变化机制还需要更深人的研究.

致谢:感谢曹继秀等在样品采集和岩芯钻探以及实验过程中给予的帮助.

\section{6 参考文献}

[ 1 ] Heinz W, Jürg B, Bütikofer J et al. Mid-to Late Holocene climate change: an overview. Quaternary Science Reviews, 2008, 27 (19/20): 1791-1828.

[ 2 ] Denton GH, Wibjörn K. Holocene climatic variations-their pattern and possible cause. Quaternary Research, 1973, 3 (2) : 155-174.

[ 3 ] Fleitmann D, Burns SJ, Mudelsee M et al. Holocene forcing of the Indian monsoon recorded in a stalagmite from Southern Oman. Science, $2003, \mathbf{3 0 0}(5626)$ : 1737-1739.

[ 4 ] Rein B, Lückge A, Sirocko F. A major ENSO anomaly during the Medieval period. Geophysical Research Letters, 2004, 31: L17211. doi : 10. 1029/2004GL. 20161.

[ 5 ] Rein B, Lückge A, Reinhardt L et al. El Niño variability off Peru during the last 20,000 years. Paleoceanography, 2005, 20: PA4003. doi: 10. 1029/2004PA001099.

[ 6 ] Clement AC, Seager R, Cane MA. Suppression of El Niño during the Mid-Holocene by changes in the Earth's orbit. Paleoceanography, 2000, $15(6): 731-737$.

[ 7 ] Rimbu N, Lohmann G, Kim JH et al. Arctic/North Atlantic Oscillation signature in Holocene sea surface temperature trends as obtained from alkenone data. Geophysical Research Letters, 2003, 30 (6) : 1280-1283.

[ 8 ] Heinz W, Solomina O, Grosjean M et al. Structure and origin of Holocene cold events. Quaternary Science Reviews, 2011, 30(21/22) : 3109-3123.

[ 9 ] An ZS, Porter SC, Kutzbach JE et al. Asynchronous Holocene optimum of the East Asian monsoon. Quaternary Science Reviews, 2000, 19(8): 743-762.

[10] Hu CY, Henderson GM, Huang JH et al. Quantification of Holocene Asian monsoon rainfall from spatially separated cave records. Earth and Planetary Science Letters, 2008, 266(3/4) : 221-232.

[11] Cai YJ, Tan LC, Cheng H et al. The variation of summer monsoon precipitation in central China since the last deglaciation. Earth and Planetary Science Letters, 2010, 291(1/2/3) : 21-31.

[12] Chen FF, Yu ZC, Yang ML et al. Holocene moisture evolution in arid central Asia and its out-of-phase relationship with Asian monsoon history. Quaternary Science Reviews, 2008, 27: 351-364.

[13] 周爱锋,孙惠玲,陈发虎等. 黄土高原六盘山天池记录的中晚全新世高分辨率气候变化及其意义. 科学通报,2010, $55(22): 2263-2266$.

[14] Sun HL, Zhou AF, Zhang XW et al. Fir trees disappeared 500 years ago in the Liupan Mountains on the southwestern Loess Plateau, China. Review of Palaeobotany and Palynology, 2011, 166(1/2) : 69-75.

[15] Oldfield F, Thompson R, Barber KE. Changing atmospheric fallout of magnetic particles record in recent ombrotrophic peat section. Science, 1978, $199(4329)$ : 679-690.

[16] Bloemendal J, Oldfield F, Thompson R. Magnetic measurements used to assess sediment influx at Llyn Goddionduon. Nature, 1979,280 : 50-53.

[17] Thompson R, Stober JC, Turner GM et al. Environmental applications of magnetic Measurements. Science, 1980 , 207 (4430) : $481-486$.

[18] 夏敦胜,马剑英,王 冠等. 环境磁学及其在西北干早区环境研究中的问题. 地学前缘,2006,13(3):108-179.

[19] Thompson R, Oldfield F. Environmental magnetism. London: Allen \& Unwin, 1986: 1-227.

[20] 邓成龙,刘青松,潘永信等. 中国黄土环境磁学.第四纪研究,2007,27(2):193-209.

[21] Thouveny N, Beaulieu J, Bonifay E et al. Climate variations in Europe over the past 140 kyr deduced from rock magnetism. Nature, 1994, 371: 503-506.

[22] 顾成军. 巢湖历史沉积记录与流域环境变化研究 [学位论文].上海:华东师范大学, 2005.

[23] 胡守云, 邓成龙,Appel E 等. 湖泊沉积物磁学性质的环境意义. 科学通报,2001,46(17):1491-1494.

[24] 刘建宝,陈发虎,陈建徽等. 山西宁武公海湖泊岩芯的环境磁学特征及中世纪暖期湿润气候探讨. 科学通报,2011, 
56 (31) :2580-2590.

[25] Dearing JA. Magnetic susceptibility. In: Walden J, Oldfield F, Smith J eds. Environmental magnetism: A practical guide No 6. London: Quaternary Research Association, 1999: 35-62.

[26] Ramsey CB. Bayesian analysis of radiocarbon dates. Radiocarbon, 2009, 51 (1) : 337-360.

[27 ] Reimer PJ, Baillie MGL, Bard E et al. Intcal 04 terrestrlal radiocarbon age calibration, $0-26$ cal kyr B. P. . Radiocarbon, 2004, 46(3) : 1029-1058.

[28] Zhao Y, Chen FH, Zhou AF et al. Vegetation history, climate change and human activities over the last 6200 years on the Liupan Mountains in the southwestern Loess Plateau in central China. Palaeogeography, Palaeoclimatology, Palaeoecolo$g y, 2010,293(1 / 2):$ 197-205.

[29] Bloemendal J, King JW, Hall FR et al. Rock magnetism of Late Neogene and Pleistocene deep-sea sediments: Relationship to sediment source, diagenetic process and sediment lithology. Journal of Geophysical Research, 1992, 97 ( B4 ) : 4361-4375.

[30 ] Wang XS, Løvlie R, Su P et al. Magnetic signature of environmental change reflected by Pleistocene lacustrine sediments from the Nihewan Basin, North China. Palaeogeography, Palaeoclimatology, Palaeoecology, 2008, 260 (3/4): 452-462.

[31] 王 冠,夏敦胜,刘秀铭等.兰州市城市街道尘埃磁学特征时空变化规律. 科学通报,2008,53(4):446-455.

[32] 李海燕. 还原成岩作用对海洋沉积物磁记录的影响及其环境学意义. 北京: 中国地质大学,2006.

[33 ] Banerjee SK, King J, Marvin J. Rapid method for magnetic granulometry with applications to environmental studies. Geophysical Research Letters, 1981, 8(4) : 333-336.

[34] Heider F, Zitzelsberger A, AbianKarl F. Magnetic susceptibility and remanent coercive force in grown magnetite crystals from $0.1 \mu \mathrm{m}$ to $6 \mathrm{~mm}$. Physics of the Earth and Planetary Interiors, 1996, 93(3/4): 239-256.

[35] 孙惠玲. 六盘山天池岩芯记录与中晚全新世气候变化研究 [学位论文]. 兰州: 兰州大学,2011.

[36] Dearing JA, Bird PM, Dann RJL et al. Secondary ferrimagnetic minerals in Welsh soils : a comparison of mineral magnetic detection methods and implications for mineral formation. Geophysical Journal International, 1997, 130(3) : 727-736.

[37] 刘宝珺. 沉积岩石学. 北京:地质出版社,1980:1-497.

[38] 徐新文, 强小科, 符超峰等. 鹤庆盆地早更新世以来湖相沉积物中早期还原成岩过程的岩石磁学证据. 第四纪研 究,2012,32(4) :812-819.

[39] 鲜本忠, 吴战国, 姜在兴等. 早期成岩作用研究进展及发展方向. 石油大学学报: 自然科学版, 2004,28(6): 133-139.

[40] 胡守云, Appel E, Hoffmann V 等. 湖泊沉积物中胶黄铁矿的鉴出及其磁学意义. 中国科学: D 辑: 地球科学, 2002,32 (3) :234-238.

[41] Peters C, Dekkers MJ. Selected room temperature magnetic parameters as a function of mineralogy, concentration and grain size. Physics and Chemistry of the Earth, 2003, 28(16-19) : 659-667.

[42] 孟庆勇, 李安春, 李铁刚等. 西菲律宾海沉积物的岩石磁学性质及其古环境意义. 自然科学进展, 2009, 19(8): 868-876.

[43] Zhou LP, Oldfield F, Wintle AG et al. Partly pedogenic origin of magnetic variations in Chinese loess. Nature, 1990, 346 : 737-739.

[44] Liu QS, Deng CL, Torrent J et al. Review of recent developments in mineral magnetism of the Chinese loess. Quaternary Science Reviews, 2007, 26(3/4) : 368-385.

[45] Zhang K, Zhao Y, Zhou AF et al. Late Holocene vegetation dynamic and human activities reconstructed from lake records in western Loess Plateau, China. Quaternary International, 2010, 227: 38-45.

[46] Dong GH, Yang Y, Zhao Y et al. Human settlement and human-environment interactions during the historical period in Zhuanglang County, western Loess Plateau, China. Quaternary International, 2012, 281 : 7-83.

[47] Wang YJ, Cheng H, Edwards RL et al. The Holocene Asian monsoon: Links to solar changes and north Atlantic climate. Science, 2005, 308(854) : 854-857.

[48] Steinhilber F, Beer J, Fröhlich C. Total solar irradiance during the Holocene. Geophysical Research Letters, 2009 , 36: L19704. doi:10. 1029/2009GL040142.

[49] 赵锡文. 古气候学概论. 北京: 地质出版社, 1992:1-176.

[50］桑广书. 黄土高原历史时期植被变化. 干旱区资源与环境,2005,19(4):54-58.

[51] 夏敦胜,杨丽萍,马剑英等. 中国北方城市大气降尘磁学特征及其环境意义. 中国科学: D 辑: 地球科学, 2007,37 (8) : $1073-1080$. 